\title{
Controlled Pilot Development Unit-Scale Fed-Batch Cultivation of Yeast on Spruce Hydrolysates
}

\author{
Andreas Rudolf, $*, \dagger$ Gaspard Lequeux,, and Gunnar Lidén ${ }^{\dagger}$
}

Department of Chemical Engineering, Lund University, Box 124, SE-221 00 Lund, Sweden and BIOMATH, Department of Applied Mathematics, Biometrics and Process Control, Ghent University, Coupure Links 653, B-9000 Gent, Belgium

\begin{abstract}
Yeast production on hydrolysate is a likely process solution in large-scale ethanol production from lignocellulose. The hydrolysate will be available on site, and the yeast has furthermore been shown to acquire an increased inhibitor tolerance when cultivated on hydrolysate. However, due to over-flow metabolism and inhibition, efficient yeast production on hydrolysate can only be achieved by well-controlled substrate addition. In the present work, a method was developed for controlled addition of hydrolysate to PDU (process development unit)-scale aerobic fedbatch cultivations of Saccharomyces cerevisiae TMB 3000. A feed rate control strategy, which maintains the ethanol concentration at a low constant level, was adapted to process-like conditions. The ethanol concentration was obtained from on-line measurements of the ethanol mole fraction in the exhaust gas. A computer model of the system was developed to optimize control performance. Productivities, biomass yields, and byproduct formation were evaluated. The feed rate control worked satisfactorily and maintained the ethanol concentration close to the setpoint during the cultivations. Biomass yields of $0.45 \mathrm{~g} / \mathrm{g}$ were obtained on added hexoses during cultivation on hydrolysate and of $0.49 \mathrm{~g} / \mathrm{g}$ during cultivation on a synthetic medium with glucose as the carbon source. Exponential growth was achieved with a specific growth rate of $0.18 \mathrm{~h}^{-1}$ during cultivation on hydrolysate and $0.22 \mathrm{~h}^{-1}$ during cultivation on glucose.
\end{abstract}

\section{Introduction}

The yeast production mode has been shown to be an important consideration when aiming at high total ethanol yield and production rate in the production of bioethanol from cellulose (1). Today much focus is put on the simultaneous saccharification and fermentation (SSF) process. One of the disadvantages with such a process is that the yeast cannot be separated from the lignin fraction and recycled but has to be produced prior to each fermentation. Efficient yeast production is therefore essential, since sugar used for yeast production could have been utilized for ethanol production. The yeast used in a lignocellulose-to-ethanol plant should preferably be produced from the cheapest substrate, i.e., cellulose or hemicellulose hydrolysates. In addition, previous research has shown that cultivation on hydrolysate produces yeast that is more resistant to the inhibitory compounds formed during hydrolysis and/or pretreatment (1). Aerobic production of yeast would most likely be the preferred method. Aerobic biomass yields are almost five times higher than anaerobic, and thus aerobic yeast production can be kept at a moderate scale, allowing most of the hemicellulose hydrolysate to be directly fermented in the fermentor vessels.

However, the aerobic cultivation of yeast on lignocellulose hydrolysate needs to be optimized. In order to reach optimal yields, over-flow metabolism and inhibition of growth due to toxic compounds in the hydrolysate have to be avoided. The most commonly used ethanol-producing yeast, Saccharomyces cerevisiae, has a maximum respiratory capacity that is less than

* To whom correspondence should be addressed. Email: andreas.rudolf@ chemeng.lth.se.

t Lund University.

$\doteqdot$ Ghent University. the total hexose (glucose and mannose) uptake potential (2). This results in mixed respiratory and fermentative hexose utilization even at fully aerobic conditions if the hexose uptake rate exceeds the critical uptake rate $(2-4)$. To avoid a decrease in cell yield due to over-flow metabolism, the hexose concentration must be kept low. Additionally, the inhibitors formed during the hydrolysis may cause decreasing cell yields (5-7). Fortunately, the yeast can convert many of the toxic compounds as long as the concentrations are low enough $(7,8)$.

Previous research has shown that by cultivation in fed-batch mode, hexose and inhibitor concentrations can be kept low, thus enabling high growth yields (9). A strict feed rate control will, however, be necessary to simultaneously obtain both optimal yield and productivity. These objectives can be achieved by a feed rate control designed to keep a low but constant ethanol concentration in the cultivation medium. Such a control can prevent inhibition because inhibition of $S$. cerevisiae during aerobic growth, on medium containing typical inhibitors found in lignocellulose hydrolysates, causes a switch to fermentative growth, i.e., ethanol is formed (10). Furthermore, optimal productivity can be reached because when the hexose uptake rate is subcritical, ethanol in the medium will be consumed and this will trigger feed rate increase.

In previous work, feed rate control in cultivations of $S$. cerevisiae based on the ethanol concentration in the cultivation medium has been shown to work satisfactorily in cultivations on glucose and molasses $(11-15)$. The feed rate control previously used was a closed-loop PI-control $(13,14)$, which was designed to maintain the ethanol concentration in the medium at a constant low level. An integral part in the controller is commonly used to eliminate the offset error. However, the previously described control method has seldom been used for 
Table 1. Model Parameters

\begin{tabular}{|c|c|c|c|}
\hline symbol & value/unit & description & source \\
\hline$K_{\mathrm{O}}$ & $1 \times 10^{-4} \mathrm{~g} / \mathrm{L}$ & $\begin{array}{l}\text { saturation constant for } \\
\text { oxygen uptake }\end{array}$ & (2) \\
\hline$K_{\mathrm{S}}$ & $0.1 \mathrm{~g} / \mathrm{L}$ & $\begin{array}{l}\text { saturation constant for } \\
\text { glucose uptake }\end{array}$ & (2) \\
\hline$K_{\mathrm{E}}$ & $0.1 \mathrm{~g} / \mathrm{L}$ & $\begin{array}{l}\text { saturation constant for } \\
\text { ethanol uptake }\end{array}$ & (2) \\
\hline$r_{\mathrm{S}} \max$ & $3.5 \mathrm{~g} /(\mathrm{g} \cdot \mathrm{h})$ & max specific glucose uptake rate & (2) \\
\hline$r_{\mathrm{O}}^{\max }$ & $0.26 \mathrm{~g} /(\mathrm{g} \cdot \mathrm{h})$ & max specific oxygen uptake rate & (2) \\
\hline$r_{\mathrm{E}}^{\mathrm{cmax}}$ & $0.5 \mathrm{~g} /(\mathrm{g} \cdot \mathrm{h})$ & $\begin{array}{l}\text { max specific ethanol consumption } \\
\text { rate }\end{array}$ & (19) \\
\hline$r_{\mathrm{Sm}}$ & $0.013 \mathrm{~g} /(\mathrm{g} \cdot \mathrm{h})$ & maintenance glucose uptake rate & (20) \\
\hline$k_{\mathrm{L}} a$ & $500 \mathrm{~h}^{-1}$ & oxygen transfer coefficient & (17) \\
\hline $\mathrm{k}_{\mathrm{E}}$ & 0.41 & ethanol evaporation constant & exp. det. \\
\hline$Y_{\mathrm{SE}}$ & $0.41 \mathrm{~g} / \mathrm{g}$ & ethanol yield on glucose & (9) \\
\hline$Y_{\text {SO }}$ & $0.41 \mathrm{~g} / \mathrm{g}$ & oxygen yield on glucose & (17) \\
\hline$Y_{\mathrm{SX}}{ }^{\mathrm{f}}$ & $0.10 \mathrm{~g} / \mathrm{g}$ & $\begin{array}{l}\text { biomass yield on glucose } \\
\text { (fermentative growth) }\end{array}$ & (18) \\
\hline$Y_{\mathrm{SX}}{ }^{\mathrm{ox}}$ & $0.48 \mathrm{~g} / \mathrm{g}$ & $\begin{array}{l}\text { biomass yield on glucose } \\
\text { (respiratory growth) }\end{array}$ & (17) \\
\hline$Y_{\mathrm{E}} O$ & $1.12 \mathrm{~g} / \mathrm{g}$ & oxygen yield on ethanol & (17) \\
\hline$Y_{\mathrm{EX}}$ & $0.72 \mathrm{~g} / \mathrm{g}$ & biomass yield on ethanol & (2) \\
\hline$Y_{\mathrm{SO}}{ }^{\mathrm{m}}$ & $1.07 \mathrm{~g} / \mathrm{g}$ & $\begin{array}{l}\text { oxygen yield on glucose } \\
\text { (maintenance) }\end{array}$ & (17) \\
\hline
\end{tabular}

cultivations on inhibitory hydrolysates and never for cultivations with a large total dilution, i.e., a large addition of substrate volume compared to the initial volume.

The aim of the current work was to adapt the control approach to more process-like cultivation conditions, addressing the critical questions above. An inhibiting dilute-acid hydrolysate from spruce was used as cultivation substrate, and the volume increase during the fed-batch cultivations was almost four-fold, a fact that made controlling the feed rate addition more arduous. A simulation model of the cultivation and the control system was developed in order to test control design and adjust control parameters. The experimental work demonstrated that high biomass yield and productivity could be achieved in fed-batch cultivations on glucose solution and hydrolysate by a well-tuned PI-control of the feed rate.

\section{Materials and Methods}

Process Modeling. A dynamic model of the fed-batch cultivation system was set up to facilitate estimation of control parameters and to examine the need for a preset exponential feed profile. The model is based on previously developed models describing aerobic cultivation of Escherichia coli (16) and S. cerevisiae $(2,17)$. The model describes how glucose uptake is distributed between oxidative metabolism, fermentative metabolism, and maintenance under restrictions set by the respiratory capacity. Values of maximum uptake and consumption rates, maintenance glucose uptake rate, and yields used in the model are given in Table 1 .

The dynamic system with component-wise mass balances can be described according to the equations:

$$
\begin{gathered}
\frac{\mathrm{d} V}{\mathrm{~d} t}=F \\
\frac{\mathrm{d}(V X)}{\mathrm{d} t}=\mu V X \\
\frac{\mathrm{d}(V S)}{\mathrm{d} t}=F S_{\text {in }}-r_{\mathrm{S}} V X
\end{gathered}
$$

$$
\begin{gathered}
\frac{\mathrm{d}(V E)}{\mathrm{d} t}=\left(r_{\mathrm{E}}-r_{\mathrm{E}}^{c}\right) V X \\
\frac{\mathrm{d}\left(V C_{\mathrm{O}}\right)}{\mathrm{d} t}=k_{\mathrm{L}} a\left(C_{\mathrm{O}}^{*}-C_{\mathrm{O}}\right) V-r_{\mathrm{O}} V X
\end{gathered}
$$

where $V, F, X, S, E$, and $C_{\mathrm{O}}$ denote the liquid volume, feed rate, cell mass concentration, glucose concentration, ethanol concentration and dissolved oxygen concentration in the bulk liquid, respectively. $\mu$ is the specific growth rate, $r_{\mathrm{S}}$ is the total specific glucose uptake rate, $r_{\mathrm{E}}$ the specific ethanol production rate, $r_{\mathrm{E}}{ }^{\mathrm{c}}$ the specific ethanol consumption rate, and $r_{\mathrm{O}}$ the specific oxygen uptake rate. $k_{\mathrm{L}} a$ is the volumetric mass transfer coefficient for oxygen, and $C_{\mathrm{O}}{ }^{*}$ the dissolved oxygen concentration in equilibrium with the gas phase.

The total sugar uptake is split between respiratory metabolism, fermentative metabolism, and maintenance:

$$
r_{\mathrm{S}}=r_{\mathrm{Sm}}+r_{\mathrm{S}}^{\mathrm{ox}}+r_{\mathrm{S}}^{\mathrm{f}}
$$

where $r_{\mathrm{Sm}}$ is the specific glucose maintenance uptake rate, $r_{\mathrm{S}}{ }^{\mathrm{ox}}$ the respiratory specific glucose uptake rate, and $r_{\mathrm{S}}{ }^{\mathrm{f}}$ the fermentative specific glucose uptake rate.

The specific growth rate, $\mu$, can be described by three terms: respiratory growth on glucose, fermentative growth on glucose, and respiratory growth on ethanol:

$$
\mu=r_{\mathrm{S}}{ }^{\mathrm{ox}} Y_{\mathrm{SX}}{ }^{o \mathrm{x}}+r_{\mathrm{S}}^{\mathrm{f}} Y_{\mathrm{SX}}{ }^{\mathrm{f}}+r_{\mathrm{E}}{ }^{\mathrm{c}} Y_{\mathrm{EX}}
$$

where $Y_{\mathrm{SX}}{ }^{\mathrm{ox}}$ is the respiratory biomass yields on glucose, $Y_{\mathrm{SX}}{ }^{\mathrm{f}}$ the fermentative biomass yield on glucose, and $Y_{\mathrm{EX}}$ the biomass yield on ethanol.

The specific oxygen consumption rate, $r_{\mathrm{O}}$, consists of three parts: oxygen consumption for respiratory growth on glucose, maintenance oxygen consumption, and oxygen consumption for respiratory growth on ethanol:

$$
r_{\mathrm{O}}=r_{\mathrm{S}}^{\mathrm{ox}} Y_{\mathrm{SO}}+r_{\mathrm{Sm}} Y_{\mathrm{SO}}^{\mathrm{m}}+r_{\mathrm{E}}^{\mathrm{c}} Y_{\mathrm{EO}}
$$

where $Y_{\mathrm{SO}}$ is the oxygen yield on glucose, $Y_{\mathrm{SO}} \mathrm{m}$ the maintenance oxygen yield on glucose, and $Y_{\mathrm{EO}}$ the oxygen yield on ethanol.

The total specific glucose uptake, $r_{\mathrm{S}}$, is assumed to follow Monod kinetics as described below:

$$
r_{\mathrm{S}}=r_{\mathrm{S}}{ }^{\max } \frac{S}{S+K_{\mathrm{S}}}
$$

where $r_{\mathrm{S}}{ }^{\max }$ is the maximum specific glucose uptake rate, and $K_{\mathrm{S}}$ the saturation constant for glucose uptake.

In the current model a maintenance term was included. Thus a fraction of the glucose is utilized for maintenance and the glucose that is not used for maintenance, $r_{\mathrm{S}}{ }^{*}$, is utilized for either respiratory or fermentative growth. The respiratory specific glucose uptake rate $r_{\mathrm{S}}{ }^{\text {ox }}$, is determined both by the glucose concentration and the dissolved oxygen concentration, i.e., $r_{\mathrm{S}}{ }^{\text {ox }}$ is the minimum value of the maximum oxidative glucose uptake rate (the first term in eq 10) and $r_{\mathrm{s}}{ }^{*}$ :

$$
r_{\mathrm{S}}{ }^{\mathrm{ox}}=\min \left(\frac{r_{\mathrm{O}}{ }^{\mathrm{max}} \frac{C_{\mathrm{O}}}{C_{\mathrm{O}}+K_{\mathrm{O}}}-r_{\mathrm{Sm}} Y_{\mathrm{SO}}^{\mathrm{m}}}{Y_{\mathrm{SO}}}, r_{\mathrm{S}}{ }^{*}\right)
$$

where $K_{\mathrm{O}}$ is the saturation constant for oxygen uptake and $r_{\mathrm{O}}{ }^{\max }$ the maximum specific oxygen uptake rate. 
At high glucose concentrations the total glucose uptake will exceed the respiratory capacity, and the growth will then become partially fermentative, i.e., ethanol will be formed:

$$
\begin{gathered}
r_{\mathrm{S}}^{\mathrm{f}}=r_{\mathrm{S}}{ }^{*}-r_{\mathrm{S}}{ }^{\mathrm{ox}} \\
r_{\mathrm{E}}=r_{\mathrm{S}}{ }^{\mathrm{f}} Y_{\mathrm{SE}}
\end{gathered}
$$

where $r_{\mathrm{E}}$ is the specific ethanol formation rate and $Y_{\mathrm{SE}}$ the ethanol yield on glucose.

Although the potential ethanol consumption follows Monod kinetics, ethanol can only be consumed if there is available respiratory capacity (2). Thus the actual specific ethanol consumption rate, $r_{\mathrm{E}}^{\mathrm{c}}$, will be the minimum value of the specific ethanol uptake rate determined by the available respiratory capacity (the first term in eq 13) and the potential specific ethanol specific uptake rate (last term in eq 13):

$$
\begin{aligned}
& r_{\mathrm{E}}^{{ }^{\mathrm{c}}=\min } \\
& \left(\frac{r_{\mathrm{O}}{ }^{\max } \frac{C_{\mathrm{O}}}{C_{\mathrm{O}}+K_{\mathrm{O}}}-r_{\mathrm{S}}{ }^{\mathrm{ox}} Y_{\mathrm{SO}}-r_{\mathrm{Sm}} Y_{\mathrm{SO}}{ }^{\mathrm{m}}}{Y_{\mathrm{EO}}}, r_{\mathrm{E}}{ }^{\mathrm{cmax}} \frac{E}{E+K_{\mathrm{E}}}\right)
\end{aligned}
$$

where $K_{\mathrm{E}}$ is the saturation constant for ethanol uptake.

Some ethanol will be lost into the exhaust gas, and the volumetric evaporation rate $q_{\mathrm{E}}^{\mathrm{v}}$ is described below:

$$
q_{\mathrm{E}}^{\mathrm{v}}=\frac{\left(x_{\mathrm{E}} k_{\mathrm{E}}\right) v_{\mathrm{air}} M_{\mathrm{E}}}{V}
$$

where $x_{\mathrm{E}}$ is the molar fraction of ethanol in the liquid, $k_{\mathrm{E}}$ a constant describing the correlation between the mole fraction of ethanol in the liquid and in the exhaust gas, $v_{\text {air }}$ the molar gas flow rate, and $M_{\mathrm{E}}$ the molar mass of ethanol.

The feed rate control is described by eqs $15-17$ :

$$
\begin{gathered}
F=K_{\mathrm{c}}\left(e+\frac{1}{T_{\mathrm{i}}} \int_{o}^{t} e d t\right)+F_{0} \exp ^{\mu_{\mathrm{r}} t} \\
e=E_{\text {setpoint }}-E_{\mathrm{t}-\mathrm{t}_{\text {delay }}}
\end{gathered}
$$

The feed rate control expression consists of two parts: the PI-control and the preset feed rate ramp; $e$ is the deviation from the setpoint concentration; $K_{\mathrm{c}}$ is the controller gain; $T_{\mathrm{i}}$ the integration time and $t$ the cultivation time, $F_{0}$ the initial feed rate, and $\mu_{\mathrm{r}}$ gives the exponential increase if a preset feed rate ramp is used. A delay time, $t_{\text {delay }}$, between the calculated ethanol concentration, $E$, and the ethanol concentration used as input to the feed rate control, $E_{t-t_{\text {delay }}}$, was included in the model (cf. eq 16). This was done to be able to simulate the effect of a slow response to feed rate changes. The response, $\Delta E$, to a certain feed rate increase, $\Delta F$, will decrease as the volume increases. Thus an equation describing $K_{\mathrm{c}}$ as a function of volume was introduced:

$$
K_{\mathrm{c}}=K_{\mathrm{c} 0} \frac{V}{V_{0}}
$$

where $V$ is the actual volume in the reactor vessel, $V_{0}$ the initial volume, and $K_{\mathrm{c} 0}$ the initial controller gain.

The simulations were carried out with or without a preset feed rate ramp (the last term in eq 15). The simulation software used was Matlab 7.0 (The Mathworks, Inc.), and the model implementation was written in Matlab-Simulink, a graphical programming interface. In Table 1 the model parameters are summarized. The aerobic yields were obtained from aerobic batch and controlled fed-batch cultivation of $S$. cerevisiae on glucose, as well as from stoichometric calculations (17) and the anaerobic yields from batch and fed-batch fermentation of glucose with $S$. cerevisiae $(9,18)$. Kinetic parameters for growth on glucose and ethanol were taken from Sonnleitner et al. (2). The microbial parameters were mainly obtained from experiments carried out in lab scale. However, they should not change even though the process is scaled up. The $k_{\mathrm{L}} a$ value depends on reactor geometry. A $k_{\mathrm{L}} a$ of $500 \mathrm{~h}^{-1}$ (at a stirrer speed of 1100 rpm with a two-blade Rushton turbine) is a rather conservative estimation.

\section{Experimental Work.}

Strain and Inoculum Preparation. The yeast used in the experiments was S. cerevisiae TMB 3000 (Dept. of Applied Microbiology, Lund University, Sweden) (21). Thirty milligrams of yeast culture from an agar plate was added to a $600-\mathrm{mL}$ Erlenmeyer flask, which contained $250 \mathrm{~mL}$ of sterile medium with a $\mathrm{pH}$ of 5.5. The medium composition was as follows: glucose $16.6 \mathrm{~g} / \mathrm{L},\left(\mathrm{NH}_{4}\right)_{2} \mathrm{SO}_{4} 7.5 \mathrm{~g} / \mathrm{L}, \mathrm{KH}_{2} \mathrm{PO}_{4} 3.5 \mathrm{~g} / \mathrm{L}, \mathrm{MgSO}_{4}$ $0.75 \mathrm{~g} / \mathrm{L}$, trace metal solution (22) $10 \mathrm{~mL} / \mathrm{L}$, and vitamin solution (22) $1 \mathrm{~mL} / \mathrm{L}$. The Erlenmeyer flask was incubated at $30{ }^{\circ} \mathrm{C}$ for $24 \mathrm{~h}$ and closed with a cotton plug.

Batch Cultivation. In order to produce yeast prior to the fedbatch cultivation, aerobic batch cultivation on glucose was carried out. A 22-L bioreactor (NLF 22, Bioengineeirng AS, Wald, Switzerland) was used and the batch volume was $4 \mathrm{~L}$. The medium composition was as follows: glucose $11 \mathrm{~g} / \mathrm{L}, \mathrm{KH}_{2-}$ $\mathrm{PO}_{4} 14 \mathrm{~g} / \mathrm{L}, \mathrm{MgSO}_{4} 3.3 \mathrm{~g} / \mathrm{L}$, trace metal solution $45 \mathrm{~mL} / \mathrm{L}$, and vitamin solution $7.5 \mathrm{~mL} / \mathrm{L}$. For $\mathrm{pH}$ adjustment and nitrogen supply, $15 \% \mathrm{NH}_{3}$ solution was used. The $\mathrm{pH}$ was maintained at 5.0, the stirrer speed was $750 \mathrm{rpm}$, and the airflow was 6 $\mathrm{L} / \mathrm{min}$.

Controlled Fed-Batch Cultivation. The substrates used were either glucose solution $(35 \mathrm{~g} / \mathrm{L})$ or a dilute acid hydrolysate from spruce. The production of the dilute acid hydrolysate has previously been described by Taherzadeh et al. (23). The sugar concentrations in the hydrolysate were as follows: glucose 23 $\mathrm{g} / \mathrm{L}$, mannose $15 \mathrm{~g} / \mathrm{L}$, galactose $3.6 \mathrm{~g} / \mathrm{L}$, and xylose $6.4 \mathrm{~g} / \mathrm{L}$. When the ethanol in the batch fermentation medium was depleted, glucose or hydrolysate was added to reach the ethanol concentration set point before the feed rate control was switched on. This was made to avoid initial instability; $14 \mathrm{~L}$ of glucose solution or hydrolysate was added during the fed-batch cultivation, which lasted for $12-15 \mathrm{~h}$. The hydrolysate was $\mathrm{pH}-$ adjusted to 4.9 with $\mathrm{NaOH}$. The stirrer speed was $1100 \mathrm{rpm}$, and the aeration rate was $14 \mathrm{~L} / \mathrm{min}$. The ethanol concentration in the cultivation liquid was estimated by measuring the ethanol fraction in the exhaust gas with a gas analyzer (1313 Fermentation Monitor, Innova, Denmark). Prior to the cultivations an accurate correlation between the ethanol concentration in the reactor and the ethanol fraction in the exhaust gas was calculated by filling the reactor with water with a known ethanol concentration and then measuring the response from the gas analyzer. These calibration experiments were performed at the same conditions as the fed-batch cultivations.

\section{Analysis.}

Cell Mass. The cell mass concentration was measured during the aerobic cell cultivation by taking triplicate $10 \mathrm{~mL}$ samples. The samples were centrifuged $(1,000 \times g)$ for $4 \mathrm{~min}$ at 3000 rpm (Z 200 A, HERMLE Labortechnik, Wehingen, Germany). The pellets washed with water, recentrifuged, dried at $105{ }^{\circ} \mathrm{C}$ for $24 \mathrm{~h}$, and subsequently weighed. 
Table 2. Cultivation Parameters Used in Simulations of Fed-Batch Cultivations

\begin{tabular}{ll}
\hline \multicolumn{1}{c}{ parameter } & value \\
\hline$X_{0}$ (initial cell mass concentration) & $4 \mathrm{~g} / \mathrm{L}$ \\
$V_{0}$ (initial volume) & $4 \mathrm{~L}$ \\
$V_{\mathrm{f}}$ (final volume) & $18 \mathrm{~L}$ \\
$S_{\text {in }}$ (hexose concentration in the feed) & $35 \mathrm{~g} / \mathrm{L}$ \\
$S_{0}$ (initial hexose concentration) & $0 \mathrm{~g} / \mathrm{L}$ \\
$E_{0}$ (initial ethanol concentration) & $0.5 \mathrm{~g} / \mathrm{L}$ \\
$F_{\max }$ (maximum feed rate) & $3.5 \mathrm{~L} / \mathrm{h}$
\end{tabular}

Substrates and Metabolites. Reactor samples were immediately filtered with $0.2 \mu \mathrm{m}$ sterile filters, and the filtered samples were stored at $-20^{\circ} \mathrm{C}$. Analysis of the most common metabolites and substrates was made using HPLC. Glucose, mannose, galactose, and xylose were separated using a polymer column (Aminex HPX-87P, Bio-Rad Laboratories, München, Germany). Ethanol, glycerol, acetate, HMF, and furfural were separated using an Aminex HPX-87H column (Bio-Rad Laboratories, München, Germany). The procedure is described in detail by Rudolf et al. (9).

\section{Simulations of Fed-Batch Control Performance}

Computer simulations allowed us to evaluate the performance of the PI-control, with or without a preset feed rate ramp, as well as to asses the need for volume compensation of the controller gain, $K_{\mathrm{c}}$. Initial cultivation parameters and constraints are given in Table 2. The same parameters were used in the cultivation experiments. The control parameters used with a preset fed-rate profile were obtained from Petersson et al. (15) and then scaled according to volume. The value of $K_{\mathrm{c} 0}$ was 28 $\times 10^{-2} \mathrm{~L}^{2} /(\mathrm{g} \cdot \mathrm{h})$ and $T_{\mathrm{i}}$ was $1.2 \mathrm{~h}$. Larger $K_{\mathrm{c} 0}\left(1.2 \mathrm{~L}^{2} /(\mathrm{g} \cdot \mathrm{h})\right)$ and shorter $T_{\mathrm{i}}(0.5 \mathrm{~h})$ had to be applied when a control without a preset feed rate ramp was simulated. The maximum feed rate was set to $3.5 \mathrm{~L} / \mathrm{h}$, as this was the maximum feed rate that could be obtained with the pump used in the cultivation experiments.

Control with Preset Feed Rate Profile. From the simulations using a preset feed rate profile around which feed rate modifications were made (eq 15), it was found that when the controller gain, $K_{\mathrm{c}}$, is not a function of volume the setpoint cannot be maintained (Figure 1). The reason is the dilution that occurs during the fed-batch. The response in ethanol concentration, $\Delta E$, to a certain feed rate increase, $\Delta F$, will decrease as the volume increases. Thus $e$ (the deviation from the setpoint concentration) has to increase during the cultivation to allow for a rapid enough feed rate increase. To maintain a small constant ethanol concentration throughout the cultivation, the controller gain, $K_{\mathrm{c}}$, must be increased substantially.

By setting $K_{\mathrm{c}}$ as a function of volume (as described in eq 17), the controller is able to maintain the ethanol setpoint more effectively, although a constant deviation from the setpoint concentration still remains (Figure 2). The deviation can be decreased by decreasing the integration time, $T_{\mathrm{i}}$, (although this might increase the instability of the system). The productivity increases as well and the cultivation is finished after $9.7 \mathrm{~h}$ as compared to $10.2 \mathrm{~h}$ when the control without volume compensation is used.

Control without Preset Feed Rate Profile. A preset feed rate ramp will, to some extent, counteract the desired control action to inhibition (caused by the accumulation of inhibitory compounds). Furthermore, the a priori estimation of $\mu$ for growth on hydrolysate is not necessarily easy, since the inhibitory properties will depend on the precise composition of the hydrolysate used. An alternative approach for cultivation on hydrolysate would therefore be to use a direct PI-control without a preset feed rate ramp, i.e., a control in which the last term of eq 15 is excluded. The simulations show that it should indeed be possible to remove the preset feed rate ramp (Figure 3) and still achieve a good control. However, the proportional and integral control parameters need to be increased considerably to compensate for the removed feed rate ramp. Furthermore, it is also shown that instability may arise if the PI parameters are suboptimal or if the delay time of the system is long (Figure 4).

\section{Experimental Results}

Control with a Preset Feed Rate Profile. Well-functioning feed rate control was obtained when using the control method based on a preset feed rate profile for the entire fed-batch cultivation on glucose solution (35 g/L) and also during the initial stages of the cultivations on hydrolysate (Figure 5). During the fed-batch cultivation on glucose, the ethanol concentration remained well under $0.5 \mathrm{~g} / \mathrm{L}$ during most of the cultivation, as predicted in the simulations (Figure 2). However, it started to increase during the last $2 \mathrm{~h}$, probably due to oxygen limitation. Exponential growth with a $\mu$ of $0.22-0.23 \mathrm{~h}^{-1}$ was achieved, and the cell yield on added sugar was approximately $0.49 \mathrm{~g} / \mathrm{g}$. In contrast, in the cultivation on hydrolysate, the ethanol concentration started to increase after $8 \mathrm{~h}$, probably due to inhibition (Figure 5). The control was not able to decrease the feed rate sufficiently; therefore further inhibition could not be prevented and exponential growth was not restored.

Control without a Preset Feed Rate Profile. In contrast to the cultivation experiments with a preset feed rate ramp, wellcontrolled cultivation on both glucose solution and hydrolysate could be achieved when a PI-control with no such feed rate ramp was used (Figure 6). During the fed-batch cultivation on glucose solution the specific growth rate was $0.22-0.23 \mathrm{~h}^{-1}$ and the biomass yield on added glucose was $0.49 \mathrm{~g} / \mathrm{g}$. Exponential growth was also obtained during cultivation on hydrolysate (Figure 6); however, not surprisingly, the specific growth rate was considerably lower, only about $0.18 \mathrm{~h}^{-1}$. The explanation for this was most likely the inhibitory nature of the hydrolysate. The biomass yield on the added hexoses (glucose, mannose, and galactose) in the cultivation on hydrolysate was $0.45 \mathrm{~g} / \mathrm{g}$, i.e., somewhat lower than on synthetic medium.

In the controlled fed-batch cultivations on hydrolysate where no preset fed rate profile was used, unstable control was sometimes a problem. As can be seen in Figure 6 there was a larger initial instability during cultivation on hydrolysate than on glucose. This initial instability was rather easily dampened by increasing $T_{\mathrm{i}}$ as suggested by the simulations. However, oscillations caused by disturbances in the ethanol signal occurred during later stages of some of the fed-batch cultivations.

\section{Discussion}

The present work demonstrates that $S$. cerevisiae TMB 3000 could be produced by controlled fed-batch cultivation on glucose solution and spruce hydrolysate with a biomass yield on hexoses as high as 0.49 and $0.45 \mathrm{~g} / \mathrm{g}$, respectively. Inhibition during cultivation on hydrolysate could be avoided by using a direct PI-control, and growth remained exponential during the entire cultivation, even though the specific growth rate was lower than that obtained on glucose.

Fed-batch cultivation of baker's yeast has traditionally been carried out on molasses, which often has a sugar concentration above $500 \mathrm{~g} / \mathrm{L}$. Also in previous work where a similar feed rate control as in the current work was used, glucose concentrations in the feed were often above $250 \mathrm{~g} / \mathrm{L}$ (Table 3). However, most lignocellulose hydrolysates only contain $40-100 \mathrm{~g} / \mathrm{L}$ of fer- 

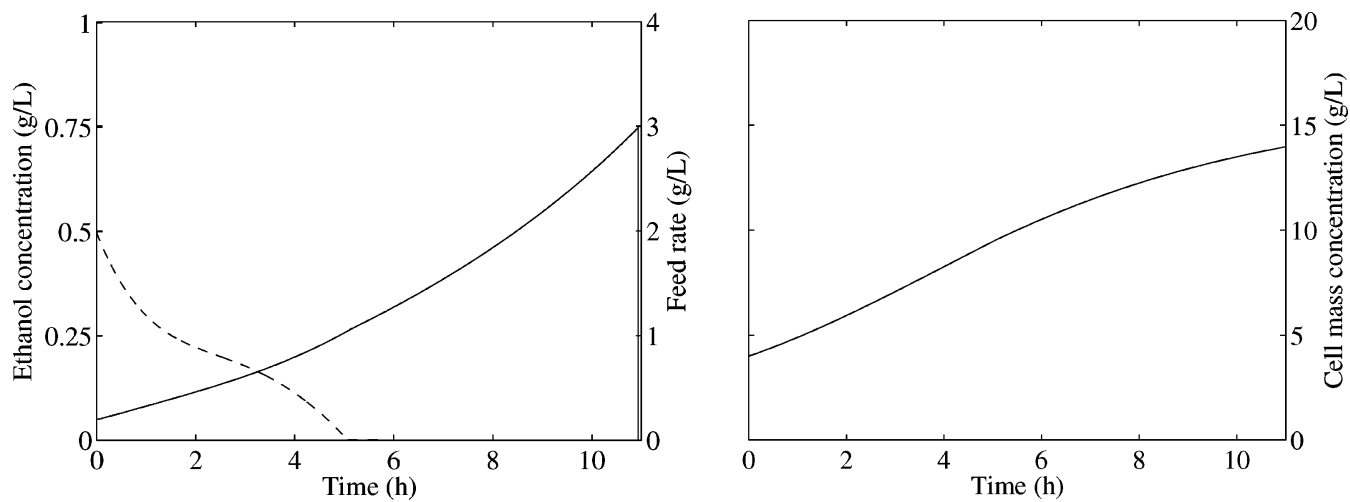

Figure 1. Simulated fed-batch cultivation on glucose with an ethanol setpoint of $0.5 \mathrm{~g} / \mathrm{L}$. A preset feed rate ramp was used $\left(\mu_{\mathrm{r}}=0.2, F_{0}=0.20\right.$ $\mathrm{L} / \mathrm{h}$ ), but there was no volume compensation of $K_{\mathrm{c}}$. Left curve: $(-)$ feed rate and (- - -) ethanol concentration, Right curve: $(-)$ cell mass concentration.
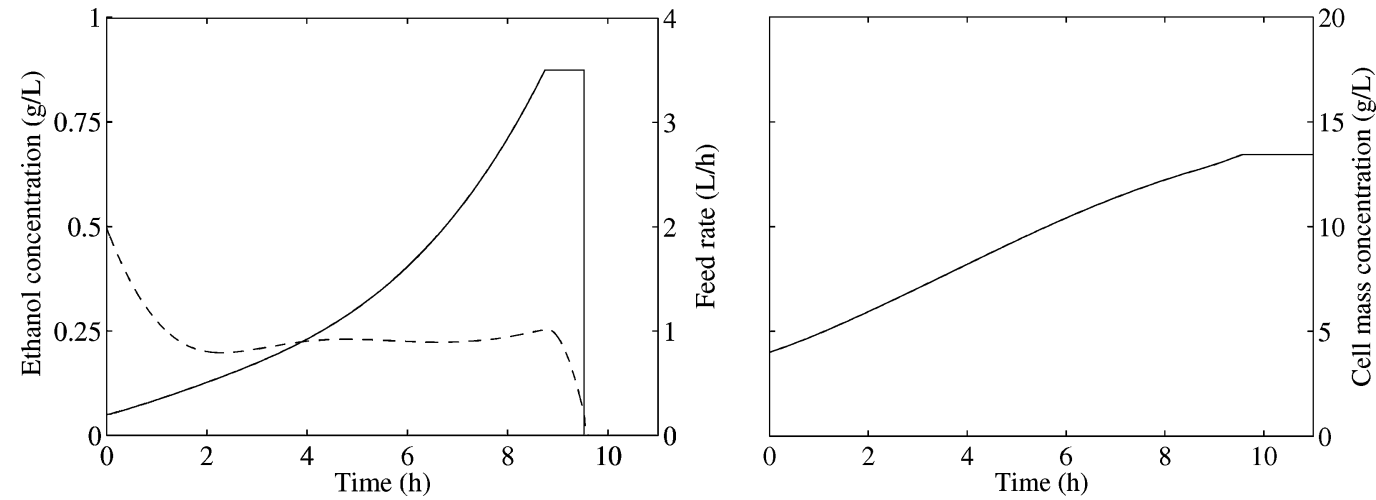

Figure 2. Simulated fed-batch cultivation on glucose with an ethanol setpoint of $0.5 \mathrm{~g} / \mathrm{L}$. A preset feed rate ramp is used $\left(\mu_{\mathrm{r}}=0.2, F_{0}=0.20 \mathrm{~L} / \mathrm{h}\right)$. The controller gain, $K_{\mathrm{c}}$, is a function of volume. Left curve: $(-)$ feed rate and (- - -) ethanol concentration, Right curve: $(-)$ cell mass concentration.
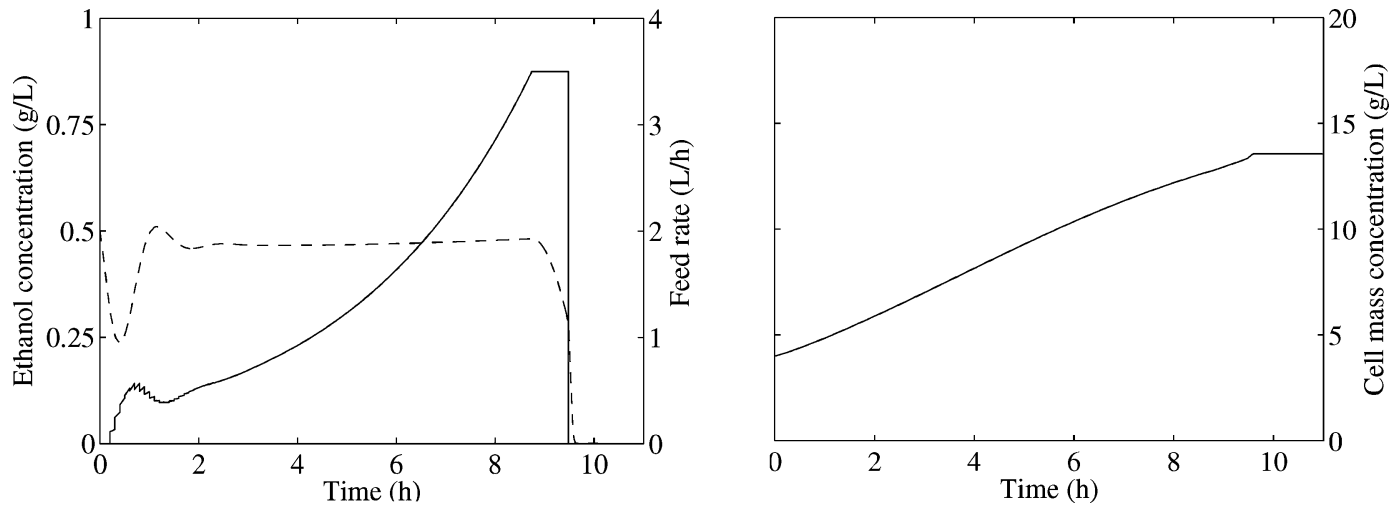

Figure 3. Simulated fed-batch cultivation on glucose. The ethanol setpoint is $0.5 \mathrm{~g} / \mathrm{L}$. No preset feed rate ramp is used, but $K_{\mathrm{c}}$ is a function of volume. The response time of the system to feed rate change is set to $0.10 \mathrm{~h}$. Left curve: ( - ) feed rate and (- -) ethanol concentration, Right curve: (-) cell mass concentration.

mentable sugars. Thus to produce enough yeast, a larger total dilution will be required in a fed-batch cultivation process based on hydrolysate. Therefore, in contrast to the previous work summarized in Table 3, the dilution in the current study was as high as 1:4.5. The volume increase thus had a real effect on the control, and this made it necessary to make the controller gain, $K_{\mathrm{c}}$, proportional to the volume. Furthermore, in all previous investigations, the scale was only $1-6 \mathrm{~L}$ compared to $18 \mathrm{~L}$ in the current work. The control strategy has previously mainly been applied with nontoxic substrates, such as molasses or glucose solutions (Table 3). However, Petersson et al. (15) used the control method in fed-batch cultivation on spruce hydrolysate and managed to avoid inhibition of cell growth. A direct PIcontrol of the feed rate was used in the current study, in contrast to previous work, where the feed rate was controlled around a preset feed ramp.
Petersson et al. (15) obtained similar biomass yields as in the current work in fed-batch cultivations on glucose and hydrolysate using the same yeast strain $(S$. cerevisiae TMB 3000) when the ethanol setpoint was $0.25 \mathrm{~g} / \mathrm{L}$. However, yields were somewhat lower when the setpoint was $0.5 \mathrm{~g} / \mathrm{L}$. Dairaku et al. (13) reached a biomass yield as high as $0.53 \mathrm{~g} / \mathrm{g}$ in fedbatch cultivations on glucose solution. The high yields might partly be explained by the low ethanol setpoint, 100-200 ppm (0.1-0.2 g/L). Cannizzaro et al. (12) and Axelsson et al. (11) obtained slightly lower yields in fed-batch cultivations on glucose and molasses, respectively.

Ethanol formation during the cultivation, necessary to maintain the concentration at a constant level despite dilution and evaporation, will cause biomass yields to decrease. This inevitable decrease in biomass yield could be maintained at a low level in the current work because the concentration setpoint 

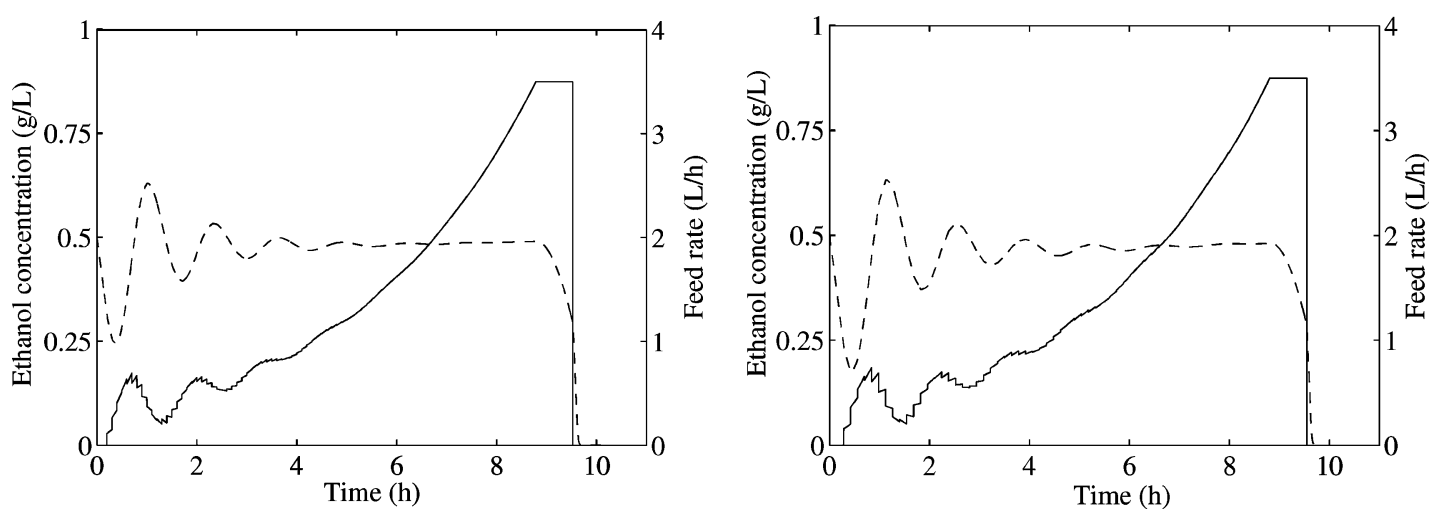

Figure 4. Simulated fed-batch cultivation on glucose showing unstable feed rate control: ( - ) feed rate and (- - -) ethanol concentration, the ethanol setpoint is $0.5 \mathrm{~g} / \mathrm{L}$. No preset feed rate ramp is used, but $K_{\mathrm{c}}$ is a function of volume. Left curve: the effect of longer delay time, $K_{\mathrm{c} 0}=1.2$ $\mathrm{L}^{2} / \mathrm{g} \cdot \mathrm{h}, T_{\mathrm{i}}=0.5 \mathrm{~h}$, and $t_{\text {delay }}=0.13 \mathrm{~h}$. Right curve: the effect of a too low $T_{\mathrm{i}}, K_{\mathrm{c} 0}=1.2 \mathrm{~L} / \mathrm{g} \cdot \mathrm{h}, T_{\mathrm{i}}=0.3 \mathrm{~h}$, and $t_{\text {delay }}=0.10 \mathrm{~h}$.
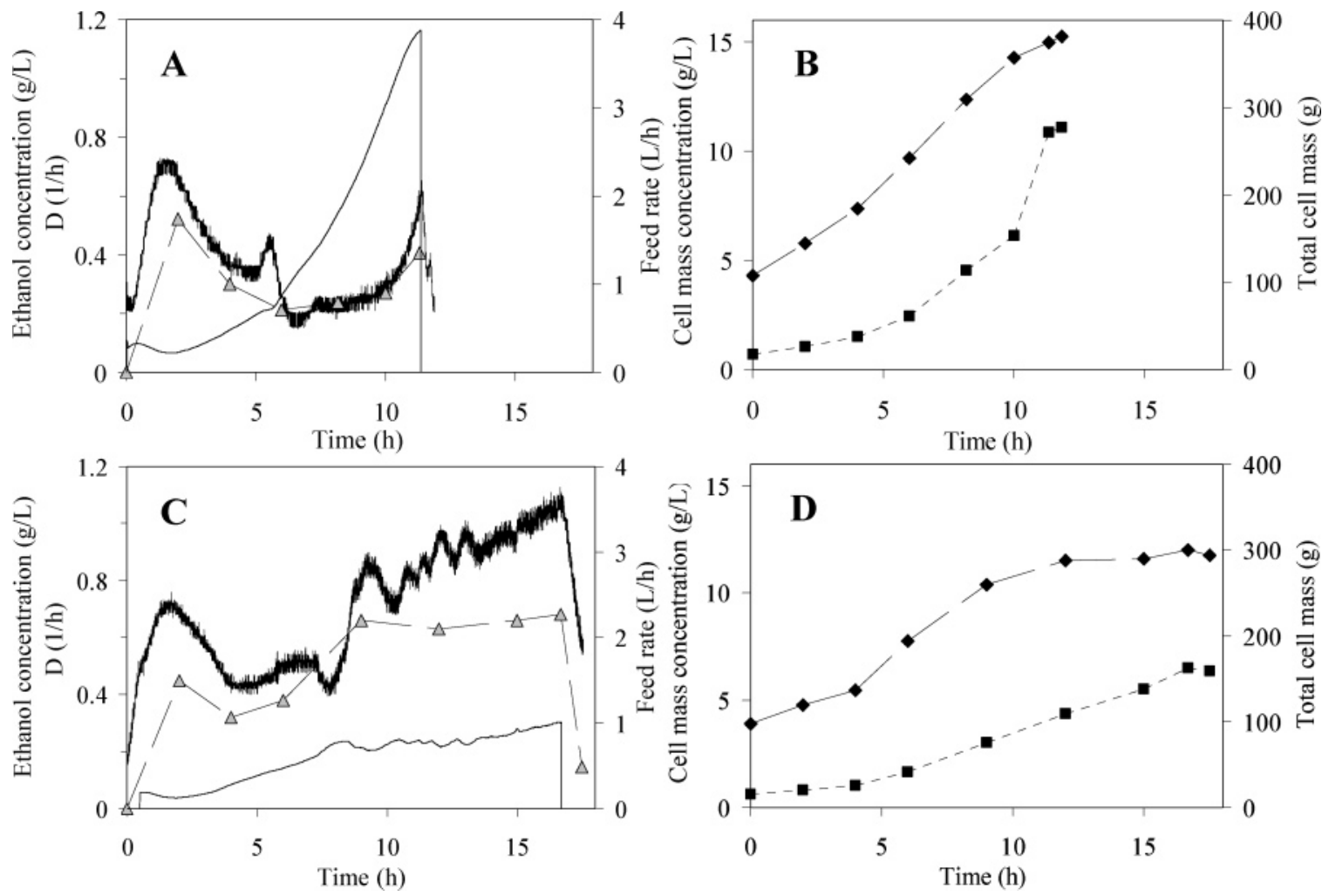

Figure 5. Ethanol, feed rate, and cell mass concentration during two fed-batch cultivations on glucose and hydrolysate. The ethanol setpoint was $0.5 \mathrm{~g} / \mathrm{L}$. A preset feed ramp was used $\left(\mu_{\mathrm{r}}=0.2 \mathrm{~h}^{-1}\right.$ and $\left.F_{0}=0.20 \mathrm{~L} / \mathrm{h}\right)$ : $(-)$ ethanol concentration from gas analyzer, $(\Delta)$ ethanol concentration measured with HPLC, (EnDash-) feed rate, $(\mathbf{\square})$ total cell mass, and $(\bullet)$ cell mass concentration. The control parameters were $K_{\mathrm{c}}=28 \times 10^{-2}$ $\mathrm{L}^{2} /(\mathrm{g} \cdot \mathrm{h})$ and $T_{\mathrm{i}}=1.2 \mathrm{~h}$. Curves A and $\mathrm{B}$, cultivation on glucose; curves $\mathrm{C}$ and $\mathrm{D}$, cultivation on hydrolysate.

was set as low as possible. During a $12 \mathrm{~h}$ cultivation, in which the ethanol concentration is $0.5 \mathrm{~g} / \mathrm{L}$ and the aeration $14 \mathrm{~L} / \mathrm{h}$, in total $11 \mathrm{~g}$ of ethanol will be formed, of which less than $2 \mathrm{~g}$ will evaporate. The residual ethanol will be reassimilated when feeding is stopped. The somewhat lower biomass yields on hydrolysate $(0.45 \mathrm{~g} / \mathrm{g})$ cannot be explained solely by the ethanol formation and evaporation. All hexoses, galactose as well, were completely consumed, and measured byproduct formation was less than $0.7 \mathrm{~g} / \mathrm{L}$. However, it is known that certain compounds formed during pretreatment and hydrolysis of lignocellulose, such as furans and organic acids, can cause a decrease in biomass yields due to an increased ATP requirement for maintenance $(5,24-26)$, which may explain the lower biomass yield obtained on hydrolyzates.

The simulations were very useful when studying the influence of the control parameters on the process dynamics. In general there was a good correlation between the simulations and the experimental work when glucose was used as substrate. The deviation from the setpoint when a PI-control with a preset feed rate ramp was used (Figure 5A) were also seen in the simulations (Figure 2). The initial oscillatory pattern observed (Figure 6A) when the ramp was removed could be predicted by the simulations as well (Figure 3). In general, however, the cultivations on glucose lasted for about $12 \mathrm{~h}$, whereas the simulations gave a cultivation time below $10 \mathrm{~h}$. This may be explained by an initial lag phase during which growth was slow; however, such a phenomenon was not included in the model. Using the model to simulate cultivation on hydrolysate was more difficult, since inhibition was not included in the model. The behavior shown in Figure 5C as well as the lower growth rates were therefore not well predicted by the simulations. The oscillatory behavior during growth on hydrolysate when no 

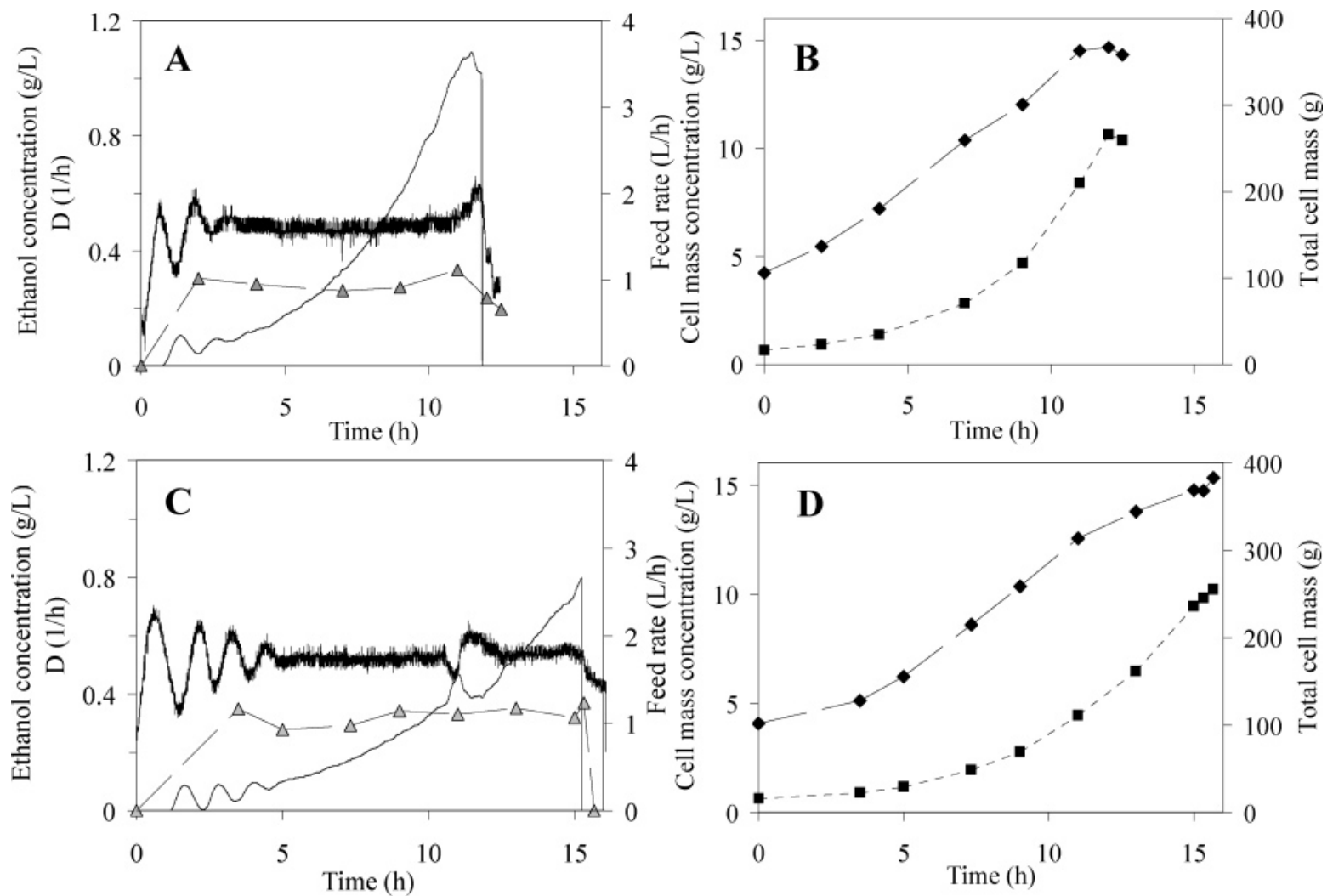

Figure 6. Ethanol, feed rate, and cell mass concentration during two fed-batch cultivations on glucose and hydrolysate. No preset feed ramp was used. The ethanol setpoint was $0.5 \mathrm{~g} / \mathrm{L}$. ( $(-)$ ethanol concentration from gas analyzer, $(\Delta)$ ethanol concentration measured with HPLC, $(-)$ feed rate, (ם) total cell mass, and $(\checkmark)$ cell mass concentration. The control parameters were $K_{\mathrm{c}}=1.2 \mathrm{~L} / \mathrm{g} \cdot \mathrm{h}$ and $T_{\mathrm{i}}=0.5 \mathrm{~h}$. Curves A and B, cultivation on glucose solution; curves $\mathrm{C}$ and $\mathrm{D}$, cultivation on hydrolysate.

Table 3. Previous Studies Using Feed Rate Control Based on Ethanol Concentration in Cultivation Medium ${ }^{a}$

\begin{tabular}{|c|c|c|c|c|c|}
\hline substrate & $\begin{array}{c}\text { final } \\
\text { volume }(\mathrm{L})\end{array}$ & $\begin{array}{l}\text { dilution during } \\
\text { fed batch }\end{array}$ & $\begin{array}{c}\text { ethanol } \\
\text { measurements }\end{array}$ & $\begin{array}{c}\text { biomass yield, } \\
Y_{\mathrm{XS}}(\mathrm{g} / \mathrm{g})\end{array}$ & author \\
\hline glucose $(\sim 300 \mathrm{~g} / \mathrm{L})$ & 2 & & teflon tubing sensor & $0.53 \mathrm{~g} / \mathrm{g}$ & Dairaku et al. (13) \\
\hline glucose $(250 \mathrm{~g} / \mathrm{L})$ & 6 & $1: 1.5$ & membrane gas sensor & & Axelsson et al. (14) \\
\hline molasses/water 1:1.2 & 6 & $\sim 1: 1.5$ & membrane gas sensor & $\sim 0.50$ & Axelsson et al. (11) \\
\hline glucose $(300 \mathrm{~g} / \mathrm{L})$ & 1.8 & $1: 3.6$ & exhaust gas analysis & $\sim 0.46$ & Cannizzaro et al. (12) \\
\hline spruce hydrolyzate & 2.5 & $1: 2.5$ & exhaust gas analysis & $\begin{array}{l}0.46 \text { (hydrolyzate) } \\
0.48 \text { (glucose) }\end{array}$ & Petersson et al. (15) \\
\hline spruce hydrolyzate & 18 & $1: 4.5$ & exhaust gas analysis & $\begin{array}{l}0.45 \text { (hydrolyzate) } \\
0.49 \text { (glucose) }\end{array}$ & current work \\
\hline
\end{tabular}

${ }^{a}$ All studies involved $S$. cerevisiae.

preset feed-rate ramp was used (Figure 6C) could, however, qualitatively be predicted by the simulations if the delay time, $t_{\text {delay, was increased. }}$

There was some deviation between the ethanol concentration measured with HPLC and the ethanol concentrations estimated with the gas analyzer (Figures 5 and 6). Most likely this is because the ethanol concentrations are so low that only a limited microbial reassimilation of ethanol during sampling will have a large relative impact. Another possibility is that fermentation products or compounds in the hydrolysate affect the ethanol sensor in the gas analyzer, resulting in a slight overestimation of the ethanol concentration.

Oscillations occurred during the later stages in some fedbatch cultivations on hydrolysate using a pure PI-controller. A control without a preset feed rate ramp will inevitably be more unstable. It was in fact possible to reproduce such oscillations in simulations by increasing the delay time of the system during the end of the cultivations to 20-30 min. According to Axelsson et al. $(14,27)$ the time constant of the system is inversely proportional to the cell mass concentration and thus the response to feed rate changes should be faster toward the end of the cultivation. However, in the current work on hydrolysate quite the opposite was observed, i.e., there was an increased response time toward the end of the cultivations. This is most likely an effect of increasing amounts of inhibitors affecting the cellular metabolism. Simulations showed that the control could be stabilized, either by decreasing the controller gain, $K_{\mathrm{c}}$, and increasing the integration time, $T_{\mathrm{i}}$, or by removing the volume compensation of $K_{\mathrm{c}}$. However, removing the volume compensation of $K_{\mathrm{c}}$ will cause the ethanol concentration to increasingly deviate from the set point during the cultivation, and this may result in impaired biomass productivity. Adding a derivative part to the control could impose better stability. However, because of measurement noise this is probably not feasible. This occasional oscillatory control pattern has to be addressed in future work.

The results clearly show that slow dynamics will make feed rate control challenging. Thus when scaling up the process to full scale, the control strategy has to be modified. Possible options could be to use a conservative control without volume compensation of $K_{\mathrm{c}}$ or to use a feed-back control only during 
the initial stage and then change to a preset and somewhat conservative open-loop exponential feed rate ramp.

Although some control issues arose, the present work clearly shows that fast and efficient cultivation of yeast on hydrolysate in PDU-scale can be achieved by a fairly simple control based on only one measured variable.

\section{Acknowledgment}

This work was financed by the Swedish Energy Administration and The EU Commission (Project NILE, Contract no. 019882).

\section{References and Notes}

(1) Alkasrawi, M.; Rudolf, A.; Lidén, G.; Zacchi, G. Influence of strain and cultivation procedure on the performance of simultaneous saccharification and fermentation of steam pretreated spruce. Enzyme Microb. Technol. 2006, 38, 279-286.

(2) Sonnleitner, B.; Käppeli, O. Growth of Saccharomyces cerevisiae is controlled by its limited respiratory capacity: formulation and verification of a hypothesis. Biotechnol. Bioeng. 1985, 28, 927937.

(3) Deken, R. H. The Crabtree Effect: A regulatory system in yeast. J. Gen. Microbiol. 1966, 44 (1), 149-156.

(4) Swanson, W. H.; Clifton, C. E. Growth and assimilation in cultures of Saccharomyces cerevisiae. J. Bacteriol. 1948, 56, 115-123.

(5) Taherzadeh, M. J.; Gustafsson, L.; Niklasson, C.; Lidén, G. Inhibition effects of furfural on aerobic batch cultivation of Saccharomyces cerevisiae growing on ethanol and/or acetic acid. $J$. Biosci. Bioeng. 2000, 90, 374-380.

(6) Banerjee, N.; Viswanthan, L. Effect of browning reaction products on cell composition of Saccharomyces cerevisiae and Aspergillus niger. Proc. Annu. Conv. Sugar Technol. Assoc. India 1976, 41, G75-G80.

(7) Taherzadeh, M. J.; Gustafsson, L.; Niklasson, C.; Lidén, G. Conversion of furfural in aerobic and anaerobic batch fermentation of glucose by Saccharomyces cerevisiae. J. Biosci. Bioeng. 1999, $87,169-174$.

(8) Villa, G. P.; Bartroli, R.; López, R.; Guerra, M.; Enrique, M.; Peñas, M.; Rodríquez, E.; Redendo, D.; Iglesias, I.; Díaz, M. Microbial transformation of furfural to furfuryl alcohol by Saccharomyces cerevisiae. Acta Biotechnol. 1992, 12, 509-512.

(9) Rudolf, A.; Alkasrawi, M.; Zacchi, G.; Lidén, G. A comparison between batch and fed-batch simultaneous saccharification and fermentation of steam-pretreated spruce. Enzyme Microb. Technol. 2005, 37, 195-204.

(10) Sárvári Horváth, I.; Franzén, C. J.; Taherzadeh, M. J.; Niklasson, C.; Lidén, G. Effects of furfural on the respiratory metabolism of Saccharomyces cerevisiae in glucose-limited chemostats. Appl. Environ. Microbiol. 2003, 69, (7), 4076-4086.

(11) Axelsson, J. P.; Mandenius, C. F.; Holst, O.; Hagander, P.; Mattiasson, B. Experience in using an ethanol sensor to control molasses feed-rates in Baker's yeast production. Bioprocess Eng. 1988, $3,1-9$.
(12) Cannizzaro, C.; Valentinotti, S.; von Stockar, U. Control of yeast fed-batch process through regulation of extracellular ethanol concentration. Bioprocess Biosyst. Eng. 2004, 26, 377-383.

(13) Dairaku, K.; Yamasaki, Y.; Kuki, K.; Shioya, S.; Tamakatsu, T. Maximum production of baker's yeast fed-batch culture by a tubing method. Biotechnol. Bioeng. 1981, XXIII, 2069-2081.

(14) Axelsson, J. P.; Hagander, P.; Holst, O.; Mandenius, C. F.; Mattiasson, B. Control of baker's yeast production based on ethanol measurement. Third European Congress on Biotechnology Munich 10-14. Sept. 1984, II, 629-634.

(15) Petersson, A.; Lidén, G. Fed-batch cultivation of Saccharomyces cerevisiae on lignocellulosic hydrolysate. Biotechnol. Lett. 2006, Epub ahead of print; DOI 10.1007/s10529-006-9227-z.

(16) Åkesson, M.; Hagander, P.; Axelsson, J. P. Probing control of fed-batch cultivations: analysis and tuning. Control Eng. Practice 2001, 9, 709-723.

(17) Rudolf, A.; Fredriksson, J. Probing control of glucose feeding in cultivation of Saccharomyces cerevisiae. Master's Thesis, Chemical Engineering, Lund University, Sweden, 2000.

(18) Rudolf, A.; Galbe, M.; Lidén, G. Controlled fed-batch fermentations of dilute-acid hydrolysate in pilot development unit scale. Appl. Biochem. Biotechnol. 2004, 113-116.

(19) Enfors, S.-O.; Hedenberg, J.; Olsson, K. Simulation of the dynamics in the Baker's yeast process. Bioprocess Eng. 1990, 5, 191-198.

(20) Stouthamer, A. H.; van Verseveld, H. W. Microbial energetics should be considered in manipulating metabolism for biotechnological purposes. TIBTECH 1987, 5, 149-160.

(21) Lindén, T.; Peetre, J.; Hahn-Hägerdal, B. Isolation and characterization of acetic acid-tolerant galactose-fermenting strains of Saccharomyces cerevisiae from a spent sulfite liquor fermentation plant. Appl. Environ. Microbiol. 1992, 58, (5), 1661-1669.

(22) Taherzadeh, M. J.; Lidén, G.; Gustafsson, L.; Niklasson, C. The effects of pantothenate deficiency and acetate addition on anaerobic batch fermentation of glucose by Saccharomyces cerevisiae. Appl. Microbiol. Biotechnol. 1996, 46, 176-182.

(23) Taherzadeh, M. J.; Eklund, R.; Gustafsson, L.; Niklasson, C.; Lidén, G. Characterization and fermentation of dilute-acid hydrolyzates from wood. Ind. Eng. Chem. Res. 1997, 36, 4659-4665.

(24) Taherzadeh, M. J.; Gustafsson, L.; Niklasson, C.; Lidén, G. Physiological effects of 5-hydroxymethylfurfural on Saccharomyces cerevisisae. Appl. Microbiol. Biotechnol. 2000, 53, 701-708.

(25) Warth, A. D. Effect of benzoic acid on growth yield of yeasts differing in their resistance to preservatives. Appl. Environ. Microbiol. 1988, 54 (8), 2091-2095.

(26) Verduyn, C.; Postma, E.; Scheffers, A.; van Dijken, J. P. Effect of benzoic acid on metabolic fluxes in yeasts: A continuous-culture study on the regulation of respiration and alcoholic fermentation. Yeast 1992, 8, 501-517.

(27) Axelsson, J. P. Experimental Techniques and data treatment for studying the dynamics of ethanol production/consumption in Baker's yeast. Anal. Chim. Acta 1988, 213, 151-163.

Received August 23, 2006. Accepted December 15, 2006.

BP060256U 